\title{
A Multifuncionalidade da Agricultura e a Função Educativa das Propriedades Rurais: experiências a partir da prática do turismo rural pedagógico
}

\section{The Multifunctionality of Agriculture and the Educational Function of Farms: experiences from the practice of pedagogical rural Tourism}

\section{La Multifuncionalidad de la Agricultura y la Función Educativa de las Fincas: experiencias a partir de la práctica del turismo rural pedagógico}

\author{
Angela Luciane Klein ${ }^{1}$
}

Marcelino de Souza ${ }^{2}$

\begin{abstract}
Resumo
A noção de multifuncionalidade da agricultura emerge como uma nova maneira de pensar a agricultura, a qual passa a desempenhar outras funções, além da produção primária de alimentos e matéria-prima. Tal característica permite que se coloquem em cena outras potencialidades da atividade agrícola que até recentemente não eram valorizadas pela sociedade. Nesse contexto, destaca-se o turismo rural pedagógico, caracterizado como um conjunto de atividades educativas realizadas no âmbito da propriedade rural, que utiliza como recurso didático as atividades agropecuárias e os recursos naturais ali existentes. Diante disso, este ensaio tem como principal objetivo realizar uma discussão em torno da noção de multifuncionalidade da agricultura e sua função educativa, tendo como foco de análise a prática do turismo rural pedagógico. Assim, por meio da utilização de pesquisas bibliográficas, constatou-se que o desenvolvimento dessa atividade, dentro da perspectiva da multifuncionalidade, favorece o aprendizado dos estudantes, estimulando a preservação dos recursos naturais e o contato com diferentes culturas. Do mesmo modo, permite ao agricultor agregar valores aos produtos e serviços produzidos em sua propriedade. Conclui-se, portanto, que as novas funções desempenhadas pela agricultura, a exemplo da função educativa, favorecem a promoção da educação ambiental e segurança alimentar, contribuindo para o desenvolvimento rural local.
\end{abstract}

Palavras-chave: multifuncionalidade da agricultura; turismo rural pedagógico; propriedades rurais educativas.

\footnotetext{
${ }^{1}$ Mestre em Desenvolvimento Rural pela Universidade Federal do Rio Grande do Sul; Graduada em Pedagogia pela Universidade Federal de Santa Maria. Professora de apoio pedagógico do Ensino Fundamental no município de Florianópolis, SC. Brasil. E-mail: angelaklain@yahoo.com.br.

${ }^{2}$ Doutor em Engenharia Agrícola pela Universidade Estadual de Campinas; Mestre em Extensão Rural pela Universidade Federal de Santa Maria; Graduado Agronomia pela Universidade Estadual de Londrina. Professor Associado do Departamento de Economia e Relações Internacionais e dos Programas de Pós-Graduação em Desenvolvimento Rural e de Agronegócios da Universidade Federal do Rio Grande do Sul (UFRGS). Brasil. Email: marcelino.souza@uol.com.br.
} 


\begin{abstract}
The notion of multifunctionality of agriculture emerges as a new way of thinking about agriculture, which starts to perform other functions in addition to the primary production of food and raw materials. This feature allows to put on scene other potential agricultural activities which until recently were not valued by society. In this context, we highlight the pedagogical rural tourism, characterized as a set of educational activities performed within the farm, which uses as teaching resource the agricultural activities and natural resources found there. In this sense, this study has as main objective to conduct a discussion around the notion of multifunctionality of agriculture and its educational function, focusing on analyzing the practice of pedagogical rural tourism. Thus, through the use of library research, it was found that the development of this activity, from the perspective of multifunctionality, promotes student learning, encouraging the preservation of natural resources and contact with different cultures. Likewise, it allows the farmer to add value to products and services produced on their own property. We conclude that the new roles played by agriculture, such as the educational function, facilitate the promotion of environmental education and food security, contributing to the local rural development.
\end{abstract}

Keywords: multifunctionality of agriculture; pedagogical rural tourism; educational farms.

\title{
Resumen
}

La noción de multifuncionalidad de la agricultura surge como una nueva forma de pensar a respecto de la agricultura, que llevarán a cabo otras funciones además de la producción primaria de alimentos y materias primas. Esta característica le permite poner en el escenario otros potenciales de la actividad agrícola que hasta hace poco tiempo no eran valorados por la sociedad. En este contexto, se destaca el turismo rural pedagógico, que se caracteriza como siendo un conjunto de actividades educativas realizadas dentro de la finca, que usa como recurso didáctico las actividades de la agricultura y los recursos naturales en el mismo. Por lo tanto, este estudio tiene como objetivo principal presentar una discusión en torno de la noción de multifuncionalidad de la agricultura y su papel educativo, centrándose en el análisis de la práctica del turismo rural pedagógico. Así, mediante el uso de investigación bibliográfica, se percibió que el desarrollo de esta actividad, desde la perspectiva de multifuncionalidad, promueve el aprendizaje del estudiante, estimulando además la preservación de los recursos naturales y el contacto con diferentes culturas. Asimismo, permite al agricultor añadir valor a los productos y servicios producidos en su propiedad. Las conclusiones, pues, que las nuevas funciones de la agricultura, tales como la función educativa, posibilitan la promoción de la educación ambiental y la seguridad alimentaria, contribuyendo al desarrollo rural local.

Palabras clave: multifuncionalidad de la agricultura; turismo rural pedagógico; fincas educativas. 


\section{Introdução}

Nas últimas duas décadas, o cenário internacional tem sido palco de uma série de discussões que visam buscar soluções para os efeitos causados pela Revolução Verde. A constatação de que o modelo produtivista trouxera sérias implicações, não apenas econômicas, mas, sobretudo, sociais e ambientais provocou a mobilização de diferentes grupos sociais ao redor do mundo, acarretando assim, um movimento de conscientização e reconhecimento das ações provocadas por esse modelo, trazendo à tona temas emergentes como a multifuncionalidade da agricultura, que se opõe à ideia de que a agricultura seja uma atividade exclusivamente produtora de bens alimentares.

Formulada dentro da estrutura europeia do início dos anos 1990, a noção de multifuncionalidade da agricultura refere-se a todos os produtos e serviços criados pelas atividades agrícolas para favorecer a economia e a sociedade como um todo. Em outras palavras, significa dizer que a agricultura, para além da simples produção de alimentos e matéria-prima, passa a desempenhar novas funções, tornando-se responsável também pela disponibilidade e qualidade dos alimentos, conservação dos recursos naturais, preservação do patrimônio cultural e reprodução socioeconômica das famílias rurais (WANDERLEY, 2003).

Dentre estas funções, destaca-se a função educativa da atividade agrícola, a qual pode ser associada à prática do turismo rural pedagógico, caracterizado por um conjunto de atividades práticas realizadas no âmbito da propriedade rural, que pode favorecer tanto os agricultores, na medida em que gera rendas complementares e a difusão de seus saberes práticos, quanto os estudantes, a partir do momento em que possibilita um aprendizado diferenciado, permitindo o contato direto com elementos da natureza e a realização de atividades práticas em um contexto que vai muito além da sala de aula.

Partindo desses pressupostos, a proposta central desse ensaio é trazer alguns elementos de discussão em torno da noção de multifuncionalidade da agricultura e sua função educativa, tendo como foco de análise a prática do turismo rural pedagógico. Nesse sentido, num primeiro momento, apresentam-se alguns aspectos conceituais e históricos da multifuncionalidade da agricultura, evidenciados no contexto europeu e, em seguida, discutese acerca das implicações e das possibilidades dessa abordagem no cenário brasileiro. 
A sessão seguinte dedica-se à análise da função educativa da agricultura e que se encontra diretamente relacionada à prática do turismo rural pedagógico no âmbito das propriedades rurais. Evidenciam-se assim os múltiplos aspectos que podem estar sendo contemplados através do desenvolvimento de atividades educativas nestas propriedades, e cujos objetivos abrangem desde a educação ambiental e alimentar das crianças até a valorização e resgate do patrimônio sociocultural do meio rural e o reconhecimento do agricultor enquanto sujeito que desempenha importantes funções em sua comunidade.

Por fim, será apresentado um conjunto de experiências envolvendo projetos de cooperação entre propriedades rurais e escolas de educação básica e que estão sendo desenvolvidas em países como a Noruega, a Finlândia, a França, a Itália, os Estados Unidos e o Japão. Tais experiências representam exemplos concretos de que a utilização das propriedades rurais como um local de aprendizagem, interação e aquisição de conhecimentos tem se constituído em uma alternativa de grande eficácia no contexto atual, possível de ser desenvolvida em diferentes contextos sociais e culturais, a exemplo do Brasil, onde já existem experiências semelhantes sendo desenvolvidas, porém, ainda pouco exploradas, sobretudo no ambiente acadêmico.

\section{A Multifuncionalidade da Agricultura no Contexto Europeu e Brasileiro: aspectos} históricos e conceituais

As discussões acerca da multifuncionalidade da agricultura tiveram início em meados da década de 1990, mais especificamente, durante a Conferência das Nações Unidas sobre o Meio Ambiente e o Desenvolvimento, realizada no Rio de Janeiro, também conhecida como a ECO-92. Foi durante esse evento que os governantes internacionais, provenientes de vários países, reconheceram o caráter multifuncional da agricultura, especialmente em relação à segurança alimentar e ao desenvolvimento sustentável (SOARES, 2000/2001).

Posteriormente, no ano de 1997, o Conselho de Ministros de Agricultura e o Conselho Europeu de Luxemburgo se pronunciaram a favor de uma agricultura europeia com caráter multifuncional, o que se constituiu no alicerce para a apresentação da proposta de reforma da Política Agrícola Comum (PAC), em março de 1998. A partir desse ano (1997), a noção de multifuncionalidade começa a ganhar maior notoriedade, passando a estar presente, de modo 
frequente, nos debates internacionais, até se transformar na principal justificativa oficial de apoio à agricultura, aprovada na Agenda 2000 (MUNIZ; SARALEGUI, 2000).

Nesse contexto, no ano de 1998, a Organização de Cooperação e de Desenvolvimento Econômico - OECD, reconhece que, além de sua função primária de produção de fibras e alimentos, a atividade agrícola pode também moldar a paisagem, prover benefícios ambientais tais como conservação dos solos, gestão sustentável dos recursos naturais renováveis e preservação da biodiversidade e contribuir para a viabilidade socioeconômica em várias áreas rurais (SOARES, 2000/2001).

Para Losch (2004) essa multifuncionalidade encontra-se situada no cruzamento de quatro principais linhas de discussões: 1) os sérios obstáculos herdados dos objetivos de política agrícola do modelo produtivista; 2) relaciona-se a uma crescente consciência ambiental; 3) as demandas de segurança alimentar; e 4) o movimento em direção à liberalização econômica no nível internacional ressalta a escala de medidas de proteção dos países industrializados.

Maluf (2002), por sua vez, ressalta que o interesse em promover uma agricultura multifuncional, reconhecendo outras funções desempenhadas pela agricultura, e que vão muito além da produção primária de alimentos e matérias-primas, emerge, sobretudo, da rigorosa avaliação acerca das formas dominantes em que a atividade agrícola era realizada e dos seus efeitos negativos em termos sociais, ambientais e culturais.

A crítica ao modelo produtivista constituiu-se, assim, no principal argumento utilizado pelos governantes europeus para justificar os rumos que as políticas públicas voltadas para o rural começaram a tomar a partir da década de 1990 (WANDERLEY, 2003).

Como resultado desse processo e visando o reconhecimento oficial e a consolidação do caráter multifuncional da agricultura na França, o governo francês, de posição esquerdista na época, passa a incorporar formalmente a noção de multifuncionalidade da agricultura na sua Lei de Orientação Agrícola (LOA), votada e promulgada no ano de 1999, estabelecendo assim os Contratos Territoriais de Estabelecimento ${ }^{3}$ (CTE). Tais contratos compreendem um conjunto de compromissos consolidados entre uma pessoa física ou jurídica que esteja

\footnotetext{
${ }^{3}$ Segundo Rémy (2003), os CTE foram substituídos pelos CAD (Contrato de Agricultura Sustentável), no ano de 2003, a partir da mudança de governo francês. Para tanto, os CAD ainda não haviam sido implementados.
} 
exercendo uma atividade agrícola, com a autoridade administrativa. Os primeiros CTE foram firmados ainda no final de 1999, e os últimos, no ano de 2002 (CANDIOTO, 2009).

Segundo Roux e Fournel (2003), a partir dessa lei, a agricultura, para além do seu papel meramente econômico, leva em conta uma realidade complexa, assegurando outros elementos importantes que configuram nesse cenário, como a função social, decorrente da criação e manutenção de empregos e da promoção de uma ocupação equilibrada do território e, a função ambiental, procedente da preservação e renovação dos recursos naturais e paisagísticos.

Para alguns teóricos (ABRAMOVAY, 2002; SOARES, 2000; 2001), no entanto, o posicionamento assumido pela União Europeia em favor da multifuncionalidade da agricultura não passa de uma estratégia protecionista, visando garantir a continuidade dos subsídios agrícolas, sem se preocupar com os impactos e efeitos negativos dessa política no contexto internacional.

Outra crítica que tem provocado discussões em âmbito internacional, refere-se à diversidade das abordagens conceituais relacionadas à multifuncionalidade da agricultura, não havendo, portanto, um conceito geral e que contemple uma visão única e homogênea de multifuncionalidade. A própria OECD (2001) evidencia essa imprecisão ao definir em seu quadro analítico duas abordagens possíveis para a multifuncionalidade: a abordagem positiva, que considera a multifuncionalidade como uma característica intrínseca à atividade econômica produtiva; e a abordagem normativa, que visualiza a multifuncionalidade a partir das múltiplas atividades que existem em torno da agricultura, sendo que certas funções podem estar sendo incentivadas por políticas públicas específicas.

Para além dessas implicações, existe ainda a polêmica que gira em torno do uso dos termos multifuncionalidade e agricultura. Conforme Carneiro (2003), a primeira dificuldade provém do viés funcionalista presente na ideia de múltiplas funções da agricultura que, de certa forma, pode ser explicado pelo intuito de se garantir o reconhecimento social e a concessão de recursos monetários às contribuições, isto é, às funções, não exclusivamente produtivas da agricultura. A segunda dificuldade com os termos empregados refere-se à utilização da expressão agricultura, que é ampliada até o ponto de englobar uma série elementos de caráter econômico, social, cultural e ambiental que configuram o mundo rural. 
Apesar das controvérsias, a noção de multifuncionalidade da agricultura representa uma importante estratégia para o desenvolvimento rural, na medida em que permite compreender a complexidade do mundo rural e as diferentes dinâmicas sociais e culturais ali existentes, favorecendo, além disso, o reconhecimento de 'novas funções' e atividades que têm emergido neste cenário.

No Brasil, uma equipe de pesquisadores vem se dedicando à investigação e análise desse tema, por meio de um conjunto de pesquisas ${ }^{4}$ realizadas em diferentes regiões do país, objetivando, a partir disso, mostrar as possibilidades oferecidas pela noção de multifuncionalidade. Entre as múltiplas funções relacionadas à agricultura, esses estudos enfatizaram quatro dimensões: reprodução socioeconômica das famílias rurais; promoção da segurança alimentar das próprias famílias rurais e da sociedade; manutenção do tecido social e cultural; preservação dos recursos naturais e da paisagem rural (WANDERLEY, 2003).

Sob essa lógica, o enfoque da multifuncionalidade permite não apenas a compreensão acerca da inserção de diferentes tipos de famílias rurais nesse universo, mas, também, a legitimação de modos de produção e de fontes de renda que, na maioria das vezes, permanece alheia aos quadros analíticos de caráter hegemônico.

\section{A Multifuncionalidade da Agricultura e sua Função Educativa}

De acordo com Losch (2004, p. 340), a noção de multifuncionalidade da agricultura compreende "todos os produtos, equipamentos e serviços criados por atividades agrícolas em benefício da economia e da sociedade em geral". Tal característica permite que se coloquem em cena várias outras potencialidades do meio rural e da atividade agrícola que, até recentemente, não eram valorizadas pela sociedade.

Nesse contexto, destaca-se um conjunto de 'novas' funções que têm favorecido o delineamento de um novo cenário no espaço rural, permitindo o inter-relacionamento entre as pessoas do meio rural e urbano e com o próprio espaço. Dentre estas funções destacam-se:

\footnotetext{
${ }^{4}$ Tais pesquisas estão relacionadas ao projeto "Estratégias de desenvolvimento rural, multifuncionalidade da agricultura e a agricultura familiar: identificação e avaliação de experiências em diferentes regiões brasileiras", apoiado pelo CNPq - COAGR. Dentre os pesquisadores envolvidos estão Maluf, Carneiro e Cazella (Carneiro, 2003).
} 
(...) a função recreativa - ligada aos espaços de lazer e às práticas lúdicorecreativas em contato com a natureza e/ou as atividades agropecuárias; a estética - associada à beleza da diversidade de cores e formas dos elementos que compõem a paisagem rural; a patrimonial - associada à conservação da biodiversidade, à manutenção das construções rurais e dos saberes-fazeres tradicionais; a social - voltada à necessidade de garantirem-se as condições de permanência e de viabilidade da agricultura, para sobrevivência das comunidades e de seus valores culturais, com base em seus próprios meios de vida; a terapêutica - relativa às propriedades terapêutico-curativas da agricultura no tratamento dos desequilíbrios e enfermidades humanas; a ambiental - que se insere como norteadora no processo de otimização de inter-relações entre a agricultura e as propriedades físicas e biológicas do ambiente natural; e a pedagógica - que se utiliza da cultura e atividades humanas, dos recursos da natureza e das sinergias geradas a partir desta interação como instrumento para a educação do ser humano (FUCKS, 2005, p. 23)

Embora apresentem suas especificidades, essas funções permitem a constituição de uma nova representação social sobre o rural, apoiada na valorização positiva da natureza e do patrimônio cultural dos espaços 'rurais' (CARNEIRO, 2003). Nesses termos, o turismo rural emerge como importante atividade que, no âmbito da multifuncionalidade, pode representar uma estratégia de desenvolvimento local, favorecendo a ativação das áreas rurais, a conservação da natureza e a criação de novos postos de trabalho.

Sznajder, Przezbórska e Scrimgeour (2009) destacam um conjunto de funções do turismo rural que evidenciam exatamente esse caráter multifuncional e que, direta ou indiretamente, estão em consonância com as atividades agrícolas. A primeira delas é a função econômica, relacionada ao estímulo do desenvolvimento agrícola e geração de renda adicional; a segunda refere-se à função espacial e ambiental, associada ao cuidado com o ambiente, proteção da natureza, utilização de edificações antigas e preservação da herança cultural rural; e por fim, a função sociopsicológica, que diz respeito à ampliação do respeito pela comunidade rural, ao entrelaçamento entre culturas urbanas e rurais, à obtenção de novas habilidades e experiências, favorecendo o aprendizado sob sua área local, sua história e atrações (SZNAJDER; PRZEZBÓRSKA; SCRIMGEOUR, 2009).

Dentro desta função, emergem ainda, as funções educativas do turismo rural, relacionadas ao aprendizado acerca do mundo rural e suas peculiaridades (natureza, herança cultural, os produtos agrícolas, as práticas dos produtores) e as oportunidade de participação no trabalho agrícola, as quais permitem aos turistas expressar sentimentos próprios e desenvolver sua 
criatividade, contribuindo ainda para a boa saúde (condições climáticas, alimentação, prática de exercícios) (SZNAJDER; PRZEZBÓRSKA; SCRIMGEOUR, 2009).

Esse conjunto de características e funções do turismo rural convergem inteiramente com os aspectos visualizados em uma nova modalidade do turismo, o Turismo Rural Pedagógico, cujo objetivo central é facilitar o processo de ensino e aprendizagem por meio da articulação teoria x prática. De acordo com a Associação Brasileira de Turismo Rural, o turismo rural pedagógico compreende:

O conjunto de atividades turísticas desenvolvidas no meio rural, comprometido com o meio ambiente e a produção agropecuária e/ou com os valores históricos de produção no universo rural, agregando valor a produtos e serviços, resgatando e promovendo o patrimônio cultural e natural da comunidade que fundamentalmente tem um acompanhamento didático pedagógico com o objetivo de aquisição de conhecimento (ABRATURR; ECA, 2005, p. 6).

Embora pareça um conceito bastante abrangente e generalista, a definição proposta pela ABRATURR se constitui em um marco importante no contexto brasileiro, na medida em que favorece o seu posterior conhecimento diante da comunidade acadêmica. Além disso, é uma definição que, de certa forma, possibilita a compreensão de que o turismo rural pedagógico, desenvolvido no âmbito das propriedades rurais, contempla diferentes dimensões, quais sejam, a social, cultural, econômica, ambiental, e educacional.

Sob essa perspectiva, as propriedades rurais passam a receber um novo enfoque, tornando-se ambientes pedagógicos valorosos que possibilitam a realização de uma ampla gama de atividades educativas, utilizando como recurso didático a produção agropecuária, a agricultura e os recursos naturais e culturais ali existentes.

A compreensão da importância atribuída às propriedades rurais, enquanto ferramentas de ensino tem se difundido de modo significativo em países como Estados Unidos, Japão e, sobretudo, da Europa Ocidental, onde diferentes projetos de cooperação entre escolas e propriedades rurais vêm sendo desenvolvidos há mais de uma década, recebendo apoio de entidades locais e incentivos dos governos, que percebendo a relevância destas ações, passaram a incluí-las na pauta das discussões. 
Em países como a França, por exemplo, a presença de inúmeras propriedades rurais pedagógicas no meio rural têm se revelado como uma atividade de caráter exemplar no quadro de um desenvolvimento sustentável. Tal constatação se deve ao fato de que essas atividades contemplam um conjunto significativo de objetivos que vão desde aspectos econômicos (rendas complementares), ecológicos (educação ambiental), patrimoniais (preservação do patrimônio histórico e paisagístico), até sociais (intercâmbio entre o urbano e o rural), favorecendo o reconhecimento do papel do agricultor e, sobretudo, da agricultura no processo de aprendizagem e valorização do meio ambiente (CAFFARELLI et al., 2010).

Conforme Caffarelli et al. (2010), no ano de 2001, uma comissão interministerial francesa, composta pelos ministérios da educação nacional, da agricultura e pesca, do desenvolvimento territorial e ambiental, da juventude e dos esportes e, recentemente, pelo ministério da justiça, publicou uma circular que definiu as estruturas e o papel das propriedades rurais que desenvolvem atividades pedagógicas, bem como, os objetivos e os tipos de públicos. De acordo com esse documento, a propriedade rural pedagógica ${ }^{5}$ caracteriza-se como uma estrutura com criação de animais e/ou culturas, que recebe crianças e jovens da escola e fora dela, podendo ser subdividida em dois tipos: as propriedades de animação e as propriedades /explorações agrícolas. A primeira compreende as propriedades urbanas ou periurbanas que apresentam pouca ou nenhuma produção agrícola, mas que dispõem de uma diversidade de espécies de animais domésticos. Já, as explorações agrícolas abrangem as propriedades rurais que, além de manter a sua função primária de produção, também desenvolvem atividades educativas, recebendo grupos de crianças e jovens regularmente (CAFFARELLI et al., 2010).

Em relação às explorações agrícolas, Tibiletti (2002) ressalta que, para se tornar uma propriedade rural pedagógica, as mesmas não precisam necessariamente fazer muito além do que já fazem. Basta continuar a desempenhar as suas atividades rotineiras e de produção, tais como, adubação, plantio, capina, irrigação, colheita de frutas, ordenha, e assim por diante.

Segundo Franco e Senni (2005), o caráter inovador presente em tal tipo de formação educativa está justamente no desenvolvimento de uma nova metodologia de ensino conhecida como "ensinar fazendo", realizada através de diferentes atividades e recursos, tais como,

\footnotetext{
${ }^{5}$ Em virtude das suas características, a expressão propriedade rural pedagógica será utilizada neste texto como sinônimo do termo turismo rural pedagógico. Conforme pesquisas, as traduções do termo fazenda pedagógica variam de acordo com cada país/idioma, porém apresentam características e finalidades bastante semelhantes.
} 
passeios educativos, aulas de ecologia ao ar livre e laboratórios de ensino. São atividades que contemplam diferentes finalidades, como por exemplo, a exposição e explicação dos processos biológicos das atividades agrícolas e da produção e processamento dos alimentos, ou ainda, de aspectos relacionados aos problemas ambientais presentes nas áreas rurais, decorrentes da má gestão dos recursos naturais.

Essa compreensão acerca do relevante papel desempenhado pelas propriedades rurais no âmbito da educação também pode ser visualizada em países como a Noruega, que desde 1995 vem desenvolvendo projetos de cooperação entre escolas e propriedades rurais, por meio da assistência da Universidade Norueguesa de Ciências da Vida (UMB). O objetivo principal da proposta, denominada de Living School, centrou-se na promoção de situações pedagógicas que permitissem aos alunos experiências de conexão ao seu meio natural, por meio de um trabalho contínuo desenvolvido junto às propriedades rurais (JOLLY et al., 2004).

Segundo Jolly et al. (2004), o governo norueguês na época, especialmente por meio do Ministério da Educação e do Ministério da Agricultura, concedeu o valor equivalente a 1 milhão de euros para o respectivo projeto, aspecto este bastante apreciado pelas autoridades escolares locais, uma vez que nesse período estavam em processo de reformulação do seu currículo escolar e cuja proposta contemplava justamente a promoção de atividades práticas que pudessem ser desenvolvidas fora da sala de aula. Os resultados obtidos com tal experiência têm sido bastante promissores, tornando-se uma referência para outros países que almejam realizar trabalho semelhante.

Outra experiência semelhante envolvendo a realização de atividades pedagógicas no âmbito das propriedades rurais está sendo desenvolvida na Finlândia. Lançado no ano de 2008, o projeto A escola vai à fazenda, caracteriza-se como um modelo de ação que tem como principal objetivo a promoção de uma educação para o desenvolvimento sustentável, por meio da interação entre sociedade e escola local e da valorização das áreas rurais e da agricultura (RISKU-NORJA; KORPELA, 2009).

Ainda no cenário europeu, destacam-se as experiências italianas que, de acordo com Napoli (2006), já no ano de 2000 compreendiam cerca de 273 quintas pedagógicas, destacando-se a região de Emilia-Romagna, com 115 propriedades rurais envolvidas com atividades educativas. Os objetivos dos projetos desenvolvidos nesta região visam, sobretudo, reforçar a 
identidade local e promover a valorização dos produtos alimentícios típicos e as explorações agrícolas.

A presença significativa desse tipo de propriedade no cenário italiano favoreceu a criação de importantes documentos voltados para a sua regulamentação e legitimação. É o caso, por exemplo, do acordo firmado no ano de 2001, que foi assinado em Roma entre a Confederação Italiana dos Agricultores (CIA) e o Ministério da Educação da Itália, visando o desenvolvimento de um projeto denominado Escolas na Fazenda com o propósito de trazer as crianças e jovens para o mundo agrícola, favorecendo o conhecimento da sua história, suas tradições culturais e suas múltiplas funções (FRANCO; SENNI, 2005).

Nesse acordo, determinou-se um conjunto de deveres e princípios a serem assumidos pela Confederação Italiana dos Agricultores (CIA), quais sejam, a organização de uma rede nacional de 'Escolas na Fazenda', a elaboração da uma carta de qualidade em âmbito nacional, o desenvolvimento de cursos de formação para os agricultores, preparação dos materiais didáticos, além de fornecer às escolas uma oferta formativa eficaz, evidenciando assim, o importante papel assumido pela agricultura no processo educativo das crianças (FRANCO; SENNI, 2005).

Dentro desse contexto, visando estabelecer parâmetros de qualidade que favorecessem práticas adequadas nas propriedades rurais pedagógicas, muitas regiões italianas passaram a adotar as denominadas 'cartas de qualidade', dentre elas, a região de Emilia-Romagna, Veneto, Piemonte, Lombardia, Abruzzo e Sardenha. Embora apresentem suas especificidades, de um modo geral, estas cartas contemplam um conjunto de regulamentos e normas semelhantes e que estão relacionadas aos aspectos de segurança e higiene, características de produção e estruturais da propriedade, a formação de competências dos agricultores empreendedores, recepção e proposta didática, bem como, a organização e a logística (BAMBI;TEI; BARBARI, 2009).

A valorização da função educativa desempenhada pela agricultura e pelos espaços rurais também está presente em países como Estados Unidos e Japão. Nos EUA, vários avanços foram feitos na última década, no sentido de incentivar o reconhecimento das propriedades rurais enquanto recurso a ser utilizado pelas escolas americanas, sobretudo, para a promoção da educação alimentar e nutricional. Conforme estimativas, no ano de 2006 existiam cerca de 
950 propriedades rurais envolvidas em programas escolares, espalhadas em mais de 35 estados americanos, e os números possivelmente aumentaram desde então. O principal argumento dos programas envolvendo propriedades rurais e escolas consiste no fato de que tais atividades apresentam um grande potencial na solução de dois desafios comuns à sociedade atual, quais sejam, as preocupações relacionadas à saúde e dieta infantil e ao desaparecimento das pequenas propriedades (JOSHI; KALB; BEERY, 2006).

Destaca-se, dentro desse cenário, o estado da Pensilvânia, que desde o ano de 2006 vem desenvolvendo um programa de cooperação entre escolas e propriedades rurais, focado em uma abordagem holística relacionada à nutrição e educação agrícola, visando desenvolver entre os alunos do jardim de infância hábitos saudáveis por meio de uma alimentação mais nutritiva através de alimentos locais. O pilar de sustentação dessas atividades concentra-se, portanto, na preocupação com aspectos relacionados à obesidade infantil e diabetes e a promoção de um estilo de vida mais saudável e sustentável (HINRICHS et al., 2008).

No Japão, por sua vez, a proposta situa-se na realização de um programa pedagógico envolvendo um grupo de agricultores donos de propriedades leiteiras que oferecem serviços de caráter educativo aos visitantes, em especial a crianças e jovens das escolas locais. O projeto vem sendo desenvolvido desde 2000, produzindo efeitos positivos em termos de aprendizagem tanto para os visitantes quanto para os próprios agricultores, ao passo que estes têm a oportunidade de descobrir novas possibilidades para a agricultura (OHE, 2009).

No cenário brasileiro já estão sendo desenvolvidas algumas experiências envolvendo a prática de atividades pedagógicas em propriedades rurais voltadas para grupos escolares, entretanto, ainda não existem referências teóricas que contemplem esse entendimento acerca das potencialidades presentes na prática do turismo rural pedagógico enquanto uma ferramenta de ensino para as escolas e uma atividade que pode contribuir para o desenvolvimento rural.

\section{Considerações Finais}

A noção de multifuncionalidade da agricultura, apesar de estar inserida nos debates internacionais há menos de duas décadas, já contempla o grupo dos principais temas da atualidade, gerando muitas polêmicas e discussões, seja pelo seu caráter funcionalista, seja 
pelos objetivos implícitos que giram em seu entorno, seja pelo modo como essa abordagem é compreendida por certos estudiosos e/ou governos.

O fato é que a multifuncionalidade da agricultura, dentro das suas limitações, passou a ser compreendida como um instrumento eficaz e com enfoque inovador que permite compreender a complexidade do mundo rural e as diferentes dinâmicas sociais e culturais ali existentes. No caso brasileiro, possibilita ainda, o reconhecimento e legitimação das múltiplas funções desempenhadas pela agricultura familiar e as suas inúmeras contribuições para o desenvolvimento rural.

Além disso, essa abordagem abre novas "portas" para o incentivo e desenvolvimento de atividades com caráter inovador, a exemplo do turismo rural pedagógico desenvolvido no âmbito das propriedades rurais. Esse tipo de atividade, analisado sob a lógica da multifuncionalidade da agricultura, sobretudo, da função educativa, favorece não apenas o aprendizado das crianças em idade escolar, mas também o cuidado e a preservação dos recursos naturais e o contato com diferentes culturas, integrando campo e cidade e valorizando espaços antes configurados como lugares atrasados. Do mesmo modo, permite ao agricultor agregar valores aos produtos e serviços produzidos em sua propriedade, fomentando consequentemente, a economia local e a geração de renda para as famílias rurais.

Trata-se, portanto, de uma importante recurso didático a ser utilizado pelas escolas públicas e privadas. Nesse contexto, outras funções correlacionadas entram em cena, a exemplo da segurança alimentar e da preservação ambiental e cultural, fortalecendo assim a ideia de que a agricultura, para além da sua função primária de produção de alimentos e matéria-prima, também contempla outras funções que podem contribuir para o desenvolvimento rural e a melhoria da qualidade de vida das famílias rurais e da sociedade em geral.

As várias experiências desenvolvidas em diferentes países e que foram apresentadas neste estudo evidenciam exatamente esses aspectos, comprovando assim, a relevância presente na promoção dessas atividades em cooperação com as escolas. É importante ressaltar que todas estas experiências tiveram algum apoio e incentivo, seja dos governos locais e/ou nacionais, seja de entidades (Universidades) ou organizações.

Nesse sentido, o reconhecimento e a valorização das funções socioeducativas desempenhadas pela agricultura a partir da prática do turismo rural pedagógico implicariam, sobretudo, na 
elaboração de políticas públicas de incentivo a essa atividade, com a participação dos setores públicos na elaboração e execução de projetos de cooperação entre escolas e propriedades rurais. Além disso, implicaria na realização de pesquisas de caráter acadêmico, por meio de estudos de caso que evidenciassem essa potencialidade.

\section{Referências}

ASSOCIAÇÃO BRASILEIRA DE TURISMO RURAL - ABRATURR; ECA Jr. Roteiro do Turismo Rural do Estado de São Paulo. 2005. Disponível em: <http.www.idestur.org.br/.../F_ROTEIRO_PEDAGOGICO_TURISMO_RURAL.pdf>. Acesso em: 17 jun. 2009.

ABRAMOVAY, R. Subsídios e multifuncionalidade na política agrícola européia. Revista de Economia e Sociologia Rural, São Paulo, v. 2, n.40, p. 235-264, 2002.

Funções e medidas da ruralidade no desenvolvimento contemporâneo. Textos para discussão, n.702. Rio de Janeiro: IPEA, 2000.

BAMBI,G.; TEI, T.; BARBARI M.Lineeguida per laprogettazione, larealizzazione e la disciplina dell'attivitàdifattoriadidattica. In: CONVEGNO NAZIONALE DELL'ASSOCIAZIONE ITALIANA DI INGEGNERIA AGRARIA, 9., 2009, Ischia Porto. Anais eletrônicos... Ischia Porto, 2009. Disponível em: <http://atlanticmoon.com:8096/Agrisocialcoop/documentazione/agricoltura/29. LINEE\%20GUIDA\%20FATTORIE\%20DIDATTICHE.pdf>. Acesso em: 20 ago. 2011.

CAFFARELLI, J.et al. Créer une fermepédagogique: de l'idée à larealization. Paris: Educagri, 2010.

CANDIOTTO, L. Z. P. Elementos para o debate acerca do conceito de turismo rural. Turismo em Análise, São Paulo, v. 21, p. 3-24, 2010. Disponível em: <http://www.turismoemanalise.org.br /index.php/turismoemanalise/article/view/69>.Acesso em: 10 fev. 2012.

CARNEIRO, M J.; MALUF, R. S. Introdução. In: MALUF, R. S.; CARNEIRO, M. J. (Org.). Para além da produção: multifuncionalidade e agricultura familiar. Rio de Janeiro: MAUAD, 2003. p.17-27.

FRANCO, S.; SENNI, S. (Ed.). La funzionesocialedell'agricoltura: Il caso del Lazio.[S.1.]:UniversitàdellaTuscia, 2005. (Quaderno ISE, n. 15). Disponível em:<www.grupponoise.it/files/doc02.pdf>. Acesso em: 30 jul. 2011.

FUCKS, P. M. Turismo, agricultura e patrimônio: São Lourenço do Sul (RS). Santa Maria: Facos/UFSM, 2005. (Série Dissertações em Turismo Rural, n. 5).

JOLLY, L. et al. The farm as a pedagogical resource: an evaluation of the co-operation between agriculture and primary school in the county of Nord-Trondelag, Norway. In: LEVENDE LAERING. Literratur. 2004. Paper submitted for the $6^{\text {th }}$ European Symposium on Farming and Rural Systems Research and Extension,Vila Real, Portugal, 2004. Disponível em: $<\mathrm{http} / / /$ www.livinglearning.org/PDF\%20documents/The_Farm_as_a_Pedagogical_Resource__Portugal .pdf>. Acessoem: 12 mar. 2011.

JOSHI, A.; KALB M.; BEERY, M. Going local: paths to success for farms to school programs. Los Angeles, CA: National Farm to School Program, Center for Food \& Justice and Community Food Security Coalition, 2006. Disponível em:<http://departments.oxy.edu/uepi/cfj/publications /goinglocal.pdf>. Acesso em: 29 ago. 2011. 
LOSCH, B. Debating the multifuncionality of agriculture: From Trade Negotiations to Development Policies by the South. Journal of Agrarian Change, Oxford, v. 4, n. 3, 2004. Disponível em <http://publications.cirad.fr/une_notice.php?dk=521448 >. Acesso em: 2 nov. 2011.

MALUF, R. S. O enfoque da multifuncionalidade da agricultura: aspectos analíticos e questões de pesquisa. In: LIMA, D. M. A; WILKISON, J. (Org.). Inovação nas tradições da agricultura familiar. Brasília: CNPq/Paralelo 15, 2002. p. 301-328.

MUNIZ, J. A.; SARALEGUI, C. T. La multifuncionalidad de la agricultura: aspectos econômicos e implicaciones sobre la política agrária. Estudios Agrosociales y Pesqueros, [Madrid?], n. 189, p. 29-48, 2000. Disponível em: $<$ http://dialnet.unirioja.es/servlet/articulo?codigo=201162>. Acesso em: 6 jan. 2011.

NAPOLI, L. A new reality for italian rural areas: educational farms. In: UniversitatDegliStudi di Trieste. Open Star Ts:l'archivioistituzionaled'Ateneo Trieste. Trieste, 2006. p. 333-335. Disponível em: <http://www.openstarts.units.it/dspace/bitstream/10077/865/1/f4napoli.pdf>. Acessoem: 15 mar. 2011.

OHE, Y. Educational function of agriculture and farm diversification: evidence from dairy Farming experience services in Japan. International Association of Agricultural Economists Conference, Beijing, China, 2009. Disponível em: 〈http://ageconsearch.umn.edu/handle/51557〉. Acesso em: março de 2011.

ORGANISATION FOR ECONOMIC CO-OPERATION AND DEVELOPMENT (OECD).Multifunctionality: towards an analytical framework. Paris: OECD, 2001. Disponível em: <www.oecd.org/dataoecd/43/31/1894469.pdf>. Acesso em: 25 nov. 2011.

RISKU-NORJA, H.; KORPELA, E. School goes to the farm: conceptualisation of rural-based sustainability education. In: CONFERENCE OF THE EUROPEAN SCIENCE EDUCATION RESEARCH ASSOCIATION,Istanbul,2009. Proceedings... Istanbul, 2009. Disponível em: <https://portal.mtt.fi/.../FarmsSchools/.../ESERA_31.8-4.9.09.pdf>. Acesso em: 25 mar. 2011.

ROUX, B.; FOURNEL, E. Multifuncionalidade e emprego nos estabelecimentos rurais franceses: um estudo nas zonas montanhosas de LanguedocRoussillon. In: MALUF, R. S.; CARNEIRO, M. J. (Org.). Para além da produção: multifuncionalidade e agricultura familiar. Rio de Janeiro: MAUAD, 2003. p.169-199.

SOARES, A.C. A multifuncionalidade da agricultura familiar. Revista Proposta, Rio de Janeiro, n.87, ano 29, p. 40-49, 2000/2001. Disponível em: 〈http:/europa.eu.int/comm/agriculture.html〉. Acesso em: 15 set. 2001.

SZNAJDER, M.; PRZEZBÓRSKA, L.; SCRIMGEOUR, F. Agritourism.Wallingford: CABI, 2009.

TIBILETTI,E. L'aziendadiventafattoriadidattica:esperto didivulgazioneambientale.Il Divulgatore, Bologna, n. 9,não paginado,2002. Disponível em: 〈http://www.ildivulgatore.it/pdf/2002/09-art4.PDF>. Acesso em: jul. 2011.

WANDERLEY, M. N. B. Prefácio. In: MALUF, R. S.; CARNEIRO, M. J. (Org.). Para além da produção: multifuncionalidade e agricultura familiar. Rio de Janeiro: MAUAD, 2003. p. 9-16.

HINRICHS, C. et al. Growing the links between farms and schools: a how-to guidebook for Pennsylvania farmers, schools and communities. Harrisburg, PA: The Center for Rural Pennsylvania, 2008. Disponível em: <http://www.farmtoschool.org/files/publications189.pdf〉. Acesso em: 22 mai. 2011.

Recebido em: 13/12/2011 ( $1^{\text {a }}$ versão $)$ - 20/08/2012 (2 $2^{\mathrm{a}}$ versão)

Aprovado em: 17/12/2012 